\title{
Práticas de utilização e perfil de contaminação microbiológica de jalecos em escola médica
}

\author{
Use practices and profile of microbiological contamination \\ of lab coats in medical school
}

Katia Liberato S. Scheidt ${ }^{1}$; Rachel L. Ribeiroㅜ; Augusto Righetti V. F. de Araújo²; Geórgia Marielle S. Chagas²; Marianna S. Carneiro²; Rubens Canuto²; Camila Cecilia O. Corbelli ${ }^{2}$

\begin{abstract}
RESUMO
Os jalecos são um veículo potencial de transmissão microbiológica e seu uso inadequado traz riscos à saúde de profissionais e da população. O objetivo deste estudo foi o de conhecer as práticas de utilização e o perfil de contaminação dos jalecos brancos usados como uniforme por docentes e discentes do Centro Universitário Serra dos Orgãos (UNIFESO). Trata-se de um estudo quantitativo, transversal e exploratório. Respeitados os princípios éticos, aplicou-se questionário sobre o modo de uso e se realizou a análise microbiológica. Os dados foram analisados de forma manual, expressos em percentuais e demonstrados por meio de tabelas. Como resultado, 73 (setenta e três) jalecos estudados apresentaram variada flora, com predomínio de cocos Gram positivos. A região do punho, a mais contaminada, apresentou em média 23 UFC por campo. Quanto ao perfil de uso, a maioria, 42, (57\%) tem idade entre 18 e 25 anos, 46 (63\%) são do sexo feminino, 27 (37\%) são acadêmicos de medicina do $3^{\circ}$ período e apenas $13(18 \%)$ são docentes. Sobre a frequência de troca do jaleco, $35(48 \%)$ trocam uma vez por semana, entretanto com inadequado manuseio. Após uso, 36 (49\%) não lavam o jaleco separadamente, 43 (58\%) não usam produto desinfetante e $54(73 \%)$ utilizam a passagem a ferro como medida complementar de contenção microbiológica. Conclui-se que há imperiosa necessidade de conscientização dos acadêmicos e docentes sobre adequados uso e manuseio do jaleco e importância da vestimenta na epidemiologia das infecções intra e extra-ambientes da saúde.
\end{abstract}

Palavras chave: Jaleco. Biossegurança. Contaminação.

\begin{abstract}
The coats are a potential microbiological transmission means and its misuse brings risks to health professionals and population. The goal of this study was to know the usage practices and the profile of contamination of the smock worn by professors and students of the University Center Serra dos Órgãos (UNIFESO). It is a quantitative study, cross-sectional and exploratory. Respecting ethical principles, a questionnaire
\end{abstract}

1. Doutor. Professor do Curso de Medicina, Centro Universitário Serra dos Órgãos - UNIFESO.

2. Acadêmico do curso de Medicina. UNIFESO
Correspondencia Katia Liberato S. Scheidt Centro Universitário Serra dos Órgãos . Faculdade de Medicina. Av. Alberto Torres, 111, Alto CEP: 25064-004 / Teresópolis/RJ kscheidt@iff.fiocruz.br

Artigo recebido em 07/04/2014 Aprovado para publicação em 18/03/2015 
on the use of the white coat was applied and the microbiological analysis was held. The data were analyzed manually, expressed in percentages and demonstrated through tables. As a result, 73 (seventy-three) coats studied showed varied flora and predominance of Gram-positive cocci. The region of the wrist, the most contaminated, presented a UFC 23 average per field. As for the usage profile, the majority, 42, $(57 \%)$ are between the ages of 18 and 25 years, $46(63 \%)$ are female, $32(44 \%)$ are medical students in the $3^{\text {rd }}$ term and only $13(18 \%)$ are professors. On the frequency of changing of lab coat, $35(48 \%)$ change it once a week, however with inappropriate handling. After use, 36 (49\%) do not wash the coat separately, $43(58 \%)$ do not use disinfectant products, 54 (73\%) use ironing as an additional measure against microbiological contamination. It is concluded that there is imperious need for awareness of scholars and professors of appropriate use/handling of the lab coat and the importance of clothing in the epidemiology of infections intra/extra health care environment.

Keywords : Lab Coat. Biosafety. Contamination.

\section{Introdução}

A introdução do uso de jaleco na assistência hospitalar, como medida de isolamento, tornou-se uma prática habitual nos hospitais desde o século XIX. ${ }^{1}$ Nos dias atuais, o jaleco é usado por profissionais da área da saúde para protegê-los da contaminação dos ambientes em que geralmente trabalham, como hospitais e laboratórios. ${ }^{2,3}$

A contaminação da pele e roupas por respingos e por toque é praticamente inevitável em ambientes de assistência à saúde. ${ }^{4}$ Desta forma, os jalecos brancos dos profissionais da área de saúde podem ser considerados o mais importante sítio de contato em termos de indumentária com pele, líquidos e secreções dos pacientes. ${ }^{5}$ Bactérias patogênicas, que podem provocar doenças, como faringites, otites, pneumonia, tuberculose e até mesmo a morte, podem ser carregadas para lugares públicos através dos jalecos. ${ }^{6,7}$

Há um número significativo de profissionais, docentes e discentes, que não trocam o jaleco branco ao se deslocarem de uma instituição a outra. Tal comportamento pode indicar o desconhecimento desses profissionais em relação à contaminação do jaleco branco e ao potencial do mesmo como veículo de transmissão de microrganismos, tanto do paciente para o profissional de saúde; quanto deste para outros pacientes; quanto de uma instituição para outra. ${ }^{5,6}$

Os jalecos brancos podem servir não apenas como veículo de transmissão de patógenos, mas também como ambiente propício para a troca de material genético entre microrganismos, provocando aquisição de diferentes mecanismos de resistência a antibióticos. $^{7}$

A ocorrência de infecções na comunidade causadas por microrganismos resistentes tornou-se um problema de importância global. Além das bactérias, os vírus, fungos e protozoários também têm se mostrado resistentes a drogas usualmente utilizadas nos tratamentos de suas infecções. ${ }^{8}$

$\mathrm{O}$ aumento da prevalência de infecções por microrganismos resistentes em ambientes de assistência à saúde frequentemente está associado a elevadas taxas de morbimortalidade. ${ }^{9}$

Os desafios para o controle desta situação, seja nos estabelecimentos de saúde, seja na comunidade, têm como foco principal a adoção de boas práticas pelos profissionais da saúde.

Diante desses achados, este estudo buscou conhecer as práticas de utilização e o perfil de contaminação de jaleco branco usado como uniforme por docentes e discentes do UNIFESO, na expectativa de contribuir para uma maior conscientização dos profissionais da saúde sobre a importância do jaleco na epidemiologia das infecções intra e extra-ambientes da saúde.

\section{Metodologia}

Optou-se por um estudo quantitativo, transversal e exploratório. ${ }^{10}$ Como foco, tomaram-se as unidades de assistência à saúde vinculadas ao UNIFESO e, como população alvo, os docentes e discentes inseridos nos cenários de prática por ocasião do estudo.

A população elegível compreendeu todos os profissionais de saúde, incluindo aqueles em formação, que realizavam assistência direta a pacientes e aceitaram participar da pesquisa.

Os entrevistados, num total de 73 (setenta e três), realizavam atividades profissionais e ou acadêmicas nos seguintes cenários de prática: Unidades Básicas de Saúde (UBS) conveniadas Rosário, 
Meudon e Sítio Assunção. As unidades de Clínica médica e Clínica cirúrgica do Hospital das Clínicas de Teresópolis - Constantino Otaviano HCT-CO e também as Clínicas da Odontologia e da Fisioterapia, no Campus -Sede.

Os pesquisadores, acadêmicos de medicina do $2^{\circ}$ e $6^{\circ}$ períodos, revisaram a literatura corrente e discutiram sobre o objeto de estudo como atividade inicial. Para a realização do teste piloto, cada um dos pesquisadores recebeu um "kit de coleta", contendo: carimbo, pacotes de gaze estéril, frasco de $50 \mathrm{ml} \mathrm{com}$ álcool 70\% (para desinfecção do carimbo); caneta marcador de superfície (para identificação da placa de petri). Todos passaram por treinamento tanto para o preenchimento do questionário, quanto para a coleta microbiológica.

As análises foram realizadas no laboratório de análises clínicas e microbiológicas da instituição em questão.

Os instrumentos de investigação utilizados foram validados durante o estudo piloto, quando pequenos ajustes foram feitos no questionário, que incluíram mais opções sobre a frequência de troca dos jalecos e excluíram a identificação do tipo de tecido.

A exclusão dessa variável considerou a dificuldade dos pesquisadores na identificação dos tecidos e considerou também os resultados obtidos em estudo semelhante, que concluiu que o tipo do tecido com o qual os jalecos eram confeccionados não influenciou os níveis de contaminação dos mesmos. ${ }^{11}$

A coleta dos dados se deu através de visitas diurnas pré-agendadas, entre outubro e novembro de 2012, pelos pesquisadores com os responsáveis pelos consultórios, clínicas e UBS conveniadas do UNIFESO, que compuseram o cenário. As informações foram colhidas in locu pelos pesquisadores, sem que o registro permitisse a identificação do docente ou discente da instituição. As abordagens aos sujeitos que compuseram a amostra ocorreram conforme a disponibilidade de placas de petri, em média, cada pesquisador realizava três coletas por visita agendada.

O questionário se constituiu de perguntas fechadas e abertas. Após a realização da entrevista, face a face com os participantes, procedeu-se à coleta das amostras microbiológicas. Foram analisadas duas áreas dos jalecos brancos relativas aos níveis de contaminação, bolso e punho. Vale destacar que todos os jalecos brancos estudados tinham a manga comprida.

Para a coleta das amostras em cada área do jaleco, utilizaram-se os procedimentos metodológicos descritos por Nesi e Col. (2006) ${ }^{11}$ através de carimbos de madeira revestidos de fórmica, medindo $6 \mathrm{~cm}$ de comprimento e $3 \mathrm{~cm}$ de largura. Na descrição metodológica, os carimbos deveriam ser esterilizados. ${ }^{11}$

Antes do teste piloto, um dos carimbos foi previamente esterilizado, como experiência, em autoclave, por 15 minutos, à temperatura de $121^{\circ} \mathrm{C}$, procedimento que danificou a fórmica, tornando a desinfecção o método de escolha. Deste modo, utilizou-se o álcool 70\% com três aplicações no mesmo sentido, em toda extensão da base do carimbo, respeitando-se a secagem completa entre as aplicações.

A desinfecção do carimbo foi realizada imediatamente antes da coleta de cada amostra. Em todos os procedimentos, aplicou-se o carimbo sob pressão manual, mediante três movimentos de vai e vem, nas regiões selecionadas: porção radial interna do punho da mão dominante e bolso inferior correspondente à mão dominante.

Em seguida, os carimbos foram impressos em placas de Agar sangue e incubados em aerobiose por 48 horas, a $37^{\circ} \mathrm{C} .{ }^{8} \mathrm{~A}$ contagem das Unidades Formadoras de Colônias (UFC) foi realizada manualmente, tomando como base a área de impressão do carimbo.

Para a identificação bacteriana utilizaram-se critérios morfotintoriais; as bactérias foram agrupadas de acordo com suas características à coloração de Gram. O método de coloração de Gram é o mais utilizado em Bacteriologia e permite a diferenciação da maioria das bactérias em 2 grupos pelas diferenças marcantes na parede celular que apresentam.

Baseado nessas diferenças de parede celular os corantes utilizados coram as bactérias Gram-positivas em roxo e as Gram-negativas em vermelho. Essas bactérias podem ser aeróbias, anaeróbias facultativas e anaeróbias. Possuem a forma de cocos, bacilos ou víbrios (bacilos encurvados). ${ }^{8}$

A pesquisa contou com apoio do Projeto de Integração Comunidade Pesquisa e Extensão (PICPE), 2012/2013, que visa a iniciação científica através da integração dos estudantes no cotidiano de suas práticas.

O projeto foi submetido ao Comitê de Ética em Pesquisa (CEP) do UNIFESO, em conformidade com a Resolução 196/96 do Conselho Nacional de Saúde para pesquisas envolvendo seres humanos ${ }^{12}$ (CAAE: 03490612.2.0000.5247). Os preceitos éticos foram seguidos, bem como a apresentação do Termo de Consentimento Livre e Esclarecido aos entrevistados (TCLE). Durante a coleta não foi registrada nenhuma recusa à participação no estudo. 
Para o tratamento dos dados, procedeu-se ao cálculo das frequências absoluta e relativa das variáveis relacionadas a: perfil (idade, sexo, categoria profissional/acadêmica, período acadêmico, cenário de prática); classificação da área de atuação conforme o risco biológico (crítico, semi-crítico, não crítico); jornada de trabalho (4 horas, 8 horas, 12 horas) e práticas de uso: frequência de troca de jaleco (diária, duas vezes na semana, semanal, quinzenal, mensal, indeterminada); local de guarda e transporte do jaleco (bol$\mathrm{sa} /$ mochila, banco do carro, guarda roupa doméstico, não guarda em local específico); lavagem do jaleco (lavagem em separado, uso de tratamento químico ou físico); trabalho em outro estabelecimento de assistência à saúde (uso do jaleco somente na unidade de trabalho ou uso do mesmo jaleco nos diferentes locais de trabalho, hábito de tomar banho antes de iniciar a outra atividade laborativa).

Para análise dos dados, utilizou-se dos recursos do programa EXCEL, onde as informações obtidas foram armazenadas, os dados quantitativos foram expressos e analisados estatisticamente em percentuais e demonstrados por meio de tabelas e gráficos.

\section{Resultados}

As análises microbiológicas dos jalecos brancos apontaram para uma colonização predominante de cocos Gram positivos. O Staphylococcus spp foi o gênero mais comum nas duas áreas analisadas (bolso e punho), seguido dos Bacilos Gram positivos e Bacilos Gram negativos.

Foram coletadas $(n=146)$ amostras, uma de cada área (bolso e punho) dos 73 jalecos brancos es- tudados. Na área do bolso, em 24 (32\%) das amostras, não houve crescimento microbiano enquanto na região do punho, 15 ( 20\%) das amostras coletadas foram negativas.

No que se refere ao percentual total de amostras positivas $(n=107)$, em $67(63 \%)$ houve crescimento de apenas uma bactéria, 37 (35\%) apresentaram crescimento de dois ou mais microrganismos em uma mesma amostra, enquanto 3 (3\%) foram contaminadas por fungos.

Quanto às características tintoriais dos isolados $(n=147)$, a prevalência foi das bactérias gram positivas correspondentes a $122(83 \%)$; as gram negativas apresentaram 25 (17\%) do total.

Morfologicamente, os cocos foram os resultados mais expressivos nas amostras analisadas.

Em relação à quantidade de colônias, a região do punho foi a mais contaminada, apresentando em média 23 Unidades Formadoras de Colônias-UFC ${ }^{8}$ por campo, enquanto que a região do bolso apresentou uma média de 10 (dez) UFC por campo.

A análise do perfil dos usuários dos jalecos brancos estudados mostrou que a maioria dos usuários, 42 (57\%), tinha idade entre 18 e 25 anos e 46 (63\%) eram do sexo feminino.

Quanto ao vínculo institucional, 32 (44\%) eram acadêmicos de medicina, 27(37\%) do $3^{\circ}$ período, apenas $13(18 \%)$ eram docentes, atuantes nos mais variados periodos acadêmicos.

Dos entrevistados, $43(59 \%)$ estavam lotados em UBS, 17 (23\%) estavam distribuídos entre as clínicas da odontologia e da fisioterapia. Os demais atuavam respectivamente no hospital, 7 (9\%), e $6(8 \%)$ em unidades de pronto atendimento.

Tabela 1: Microrganismos recuperados nas áreas de bolso e punho dos jalecos de docentes e discentes em escola de saúde. UNIFESO 2013 Teresópolis/RJ

\begin{tabular}{lll}
\hline Áreas analisadas & N & $\%$ \\
\hline Bolso & & \\
Não houve crescimento microbiano & 24 & 32 \\
Um microrganismo recuperado & 33 & 45 \\
Mais que um microorganismo recuperado & 16 & 22 \\
Punho & & 20 \\
Não houve crescimento & 15 & 47 \\
Um microrganismo recuperado & 34 & 33 \\
Mais que um microorganismo recuperado & 24 & \\
\hline
\end{tabular}




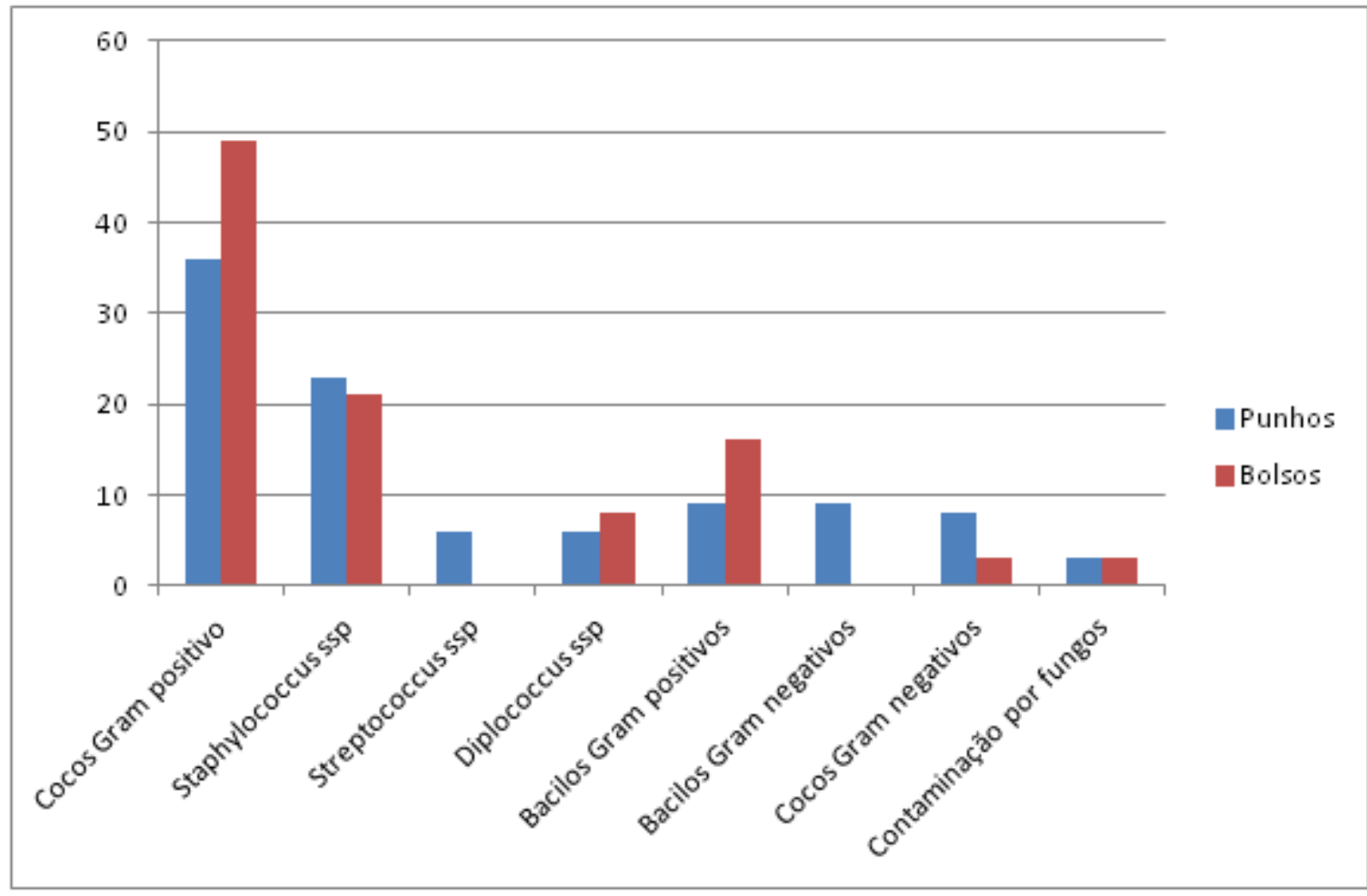

Figura 1: Microrganismos recuperados nas áreas de bolso e punho dos jalecos brancos de docentes e discentes em escola de saúde. UNIFESO 2013 Teresópolis/RJ

Ao que se refere a classificação da área de atuação conforme o risco, a maioria, 44(60\%) estavam inseridos em cenários semi críticos e 47 (64\%) cumpriam jornada de 4 horas diárias.

Quanto ao comportamento relativo à frequência de troca do jaleco branco, quase a metade, 35 (48\%), informou trocar uma vez por semana.

Durante o uso, a maioria, 39 (53\%), utilizava a mochila/bolsa para a guarda de seus jalecos, $12(16 \%)$ guardavam junto a outras peças de roupa, no armário ou cabide, em ambiente doméstico, 3 (4\%) informaram não haver lugar específico para a guarda, enquanto outros, 19 (26\%), informaram utilizar o banco do carro como cabide para a guarda da referida indumentária.

Após uso, quase a metade dos sujeitos, 36 (49\%), não lavavam o jaleco separadamente e 43 $(58 \%)$ não usavam produto desinfetante. No entanto, $54(73 \%)$ utilizavam passagem a ferro como medida complementar de contenção microbiológica.

Dos pesquisados, apenas $8(11 \%)$ informaram outro vínculo profissional. Destes, 6(75\%) atuavam em área crítica, ou seja, hospital e unidade de pronto atendimento. Os outros, 2 (25\%), desenpenhavam as atividades em área não crítica, como consultórios especializados.

Neste grupo de profissionais, quando perguntados sobre o uso de jalecos nos outros serviços, a maioria, 6 (75\%), informou usar jalecos distintos para cada unidade de trabalho, enquanto 2 (25\%) destes disseram usar o mesmo jaleco nos diferentes locais de trabalho.

Dentre os profissionais que trabalhavam em outros serviços da área da saúde, 5 (62\%) informaram que costumavam tomar banho entre uma atividade e outra, enquanto 3 (38\%) justificaram falta de tempo, na maioria das vezes.

\section{Discussão}

Ainda que os resultados microbiológicos deste estudo sejam muito genéricos, estes se coadunam às conclusões de outros estudos que mostraram que jalecos tornam-se progressivamente contaminados durante os atendimentos clínicos. ${ }^{4,5,7,13} \mathrm{O}$ contato com pacientes faz com que os jalecos se tornem colonizados com bactérias patogênicas. . $^{71,13}$ 
Tabela 2: Distribuição dos participantes do estudo de acordo com as variáveis sóciodemográficas $(\mathrm{n}=73)$. UNIFESO-Teresópolis 2013

\begin{tabular}{|c|c|c|}
\hline Variável & $\mathbf{N}$ & $\%$ \\
\hline \multicolumn{3}{|l|}{ Sexo } \\
\hline Feminino & 46 & 63 \\
\hline Masculino & 27 & 37 \\
\hline \multicolumn{3}{|l|}{ Idade } \\
\hline $18-25$ anos & 42 & 57 \\
\hline $26-30$ anos & 16 & 19 \\
\hline $31-40$ anos & 8 & 10 \\
\hline Mais de 40 anos & 7 & 9 \\
\hline \multicolumn{3}{|l|}{ Formação Profissional } \\
\hline Acadêmico Enfermagem & 4 & 5 \\
\hline Acadêmico Medicina & 32 & 44 \\
\hline Acadêmico Odontologia & 12 & 16 \\
\hline Acadêmico Fisioterapia & 5 & 7 \\
\hline Docente & 13 & 18 \\
\hline Outro & 7 & 9 \\
\hline \multicolumn{3}{|l|}{ Período acadêmico } \\
\hline $1^{0}$ & 2 & 3 \\
\hline $2^{0}$ & 6 & 8 \\
\hline $3^{0}$ & 27 & 37 \\
\hline $4^{0}$ & 5 & 7 \\
\hline $5^{0}$ & 0 & 0 \\
\hline $6^{0}$ & 8 & 11 \\
\hline $7^{0}$ & 5 & 7 \\
\hline $8^{0}$ & 1 & 1 \\
\hline $8^{0}$ ao $12^{0}$ & 0 & 0 \\
\hline Outro & 19 & 26 \\
\hline \multicolumn{3}{|c|}{ Cenário de prática profissional/acadêmica } \\
\hline UBS & 43 & 59 \\
\hline Hospital & 7 & 9 \\
\hline Clínica Odontologia e Fisioterapia & 17 & 23 \\
\hline Ambulatório & 6 & 8 \\
\hline \multicolumn{3}{|l|}{ Classificação da área conforme risco } \\
\hline Crítico & 25 & 34 \\
\hline Semicrítico & 44 & 60 \\
\hline Não crítico & 4 & 6 \\
\hline \multicolumn{3}{|l|}{ Jornada de trabalho } \\
\hline 4 horas & 47 & 64 \\
\hline 8 horas & 22 & 30 \\
\hline 12 horas & 4 & 6 \\
\hline
\end{tabular}


Tabela 3: Distribuição das variáveis comportamentais sobre o uso de jalecos por docentes e discentes do UNIFESO $(n=73)$. Teresópolis 2013

\begin{tabular}{lcc}
\hline Variáveis & N & $\%$ \\
\hline Frequência de troca do jaleco & 4 & 5 \\
Diária & 35 & 48 \\
Semanal & 14 & 19 \\
Duas vezes na semana & 9 & 12 \\
Quinzenal & 6 & 8 \\
Mensal & 5 & 7 \\
Não lembra & & 53 \\
Local de guarda do Jaleco & 39 & 26 \\
Bolsa/Mochila & 19 & 16 \\
Banco do carro & 12 & 4 \\
Armário/ cabide ambiente doméstico & 3 & 41 \\
Não há local de guarda específico & & 49 \\
Sobre a lavagem do Jaleco & 30 & 10 \\
Lava separado & 36 & 41 \\
Não lava separado & 7 & 45 \\
Não sabe informar sobre lavagem & 30 & 13 \\
Utiliza produto desinfetante & 33 & 74 \\
Não utiliza produto desinfetante & 10 & 19 \\
Não sabe informar sobre uso de desinfetante & & 7 \\
Sobre passar o jaleco a ferro & 54 & \\
Passa a ferro & 14 & 5 \\
Não passa a ferro & & \\
Não sabe & & \\
\hline
\end{tabular}

Tabela 4: Distribuição das variáveis comportamentais sobre o uso de jalecos por docentes e discentes do UNIFESO em outro serviço da área da saúde (n=8). Teresópolis 2013

\begin{tabular}{lll}
\hline Variáveis & N & $\%$ \\
\hline Cenário de prática & & 37 \\
Hospital & 3 & 37 \\
Pronto atendimento & 3 & 25 \\
Ambulatório & 2 & \\
Classificação da área conforme risco & & 75 \\
Crítico & 6 & 0 \\
Semicrítico & 0 & 25 \\
Não crítico & 2 & 25 \\
Uso de jaleco em outro serviço & & 75 \\
Usa o mesmo jaleco & 2 & 62 \\
Usa jaleco diferente & 6 & 38 \\
Sobre tomar banho antes de iniciar a outra atividade & & \\
Toma banho & 5 & \\
Não toma banho & 3 & \\
\hline
\end{tabular}


A contaminação também ocorre através da microbiota do próprio usuário para o jaleco ${ }^{1}$. A colonização da pele do profissional de saúde pode ser modificada mediante contato com pacientes colonizados ou infectados com cepas de importância epidemiológica. ${ }^{2,5}$

Estudos que avaliaram a contaminação de jalecos também constataram as mangas, especialmente na região do punho, como locais mais propícios à contaminação decorrente do cuidado ao paciente e até mesmo devido ao contato com fômites e superfícies do ambiente de assistência à saúde. , $^{4,5}$ A proximidade com as mãos favorece a colonização das mangas por microrganismos comensais ${ }^{4}$, como é o caso dos Staphylococcus ${ }^{14}$, que neste estudo representou a maioria dentre os microrganismos recuperados nos jalecos brancos estudados.

Destaca-se que a higienização adequada das mãos pode minimizar a colonização, reduzindo a flora transitória. ${ }^{15}$ As mãos representam um importante elo na epidemiologia das infecções, são consideradas a principal via de transmissão de microrganismos para a ocorrência das Infecções Relacionadas a Ambiente de Assistência à Saúde (IRAS). ${ }^{6,16}$

A disseminação das IRAS, frequentemente, advém da contaminação cruzada. ${ }^{9,16}$ As IRAS são adquiridas após a admissão do paciente com manifestação, durante a internação ou posteriormente à alta, quando relacionadas à internação ou aos procedimentos hospitalares. ${ }^{16}$ Portanto, podem ocorrer em todos os níveis de atenção à saúde, como serviços ambulatoriais e assistência domiciliar.

Ressalta-se nos resultados deste estudo que mais da metade dos entrevistados estavam lotados nas UBS $43(59 \%)$, classificadas como áreas semi-críticas e, portanto, com médio risco biológico. A maioria dos jalecos estudados, daqueles que frequentavam o referido cenário, apresentou importante contaminação.

O avanço nas políticas públicas relativas à assistência comunitária tem contribuído para que muitos cuidados médicos sejam oferecidos fora dos hospitais, ocorrendo aumento progressivo de atendimento nas UBS. A prevalência de bactérias resistentes presentes nos estabelecimentos de saúde pode variar de acordo com o tipo de atendimento prestado em cada instituição. ${ }^{9}$

A presença de microrganismos resistentes, como os Staphylococcus aureus resistentes à meticilina, nos jalecos de estudantes de medicina utilizados em locais de assistência à saúde ${ }^{17,18}$, sugere risco de disseminação de microrganismos nos ambientes intra e extra-hospitalar. ${ }^{13}$

Estima-se que 90\% das Infecções Relacionadas à Saúde-( IRAS) são causadas por bactérias resistentes, as enterobactérias, e os Staphylococcus aureus são os principais microrganismos causadores de infecção ${ }^{9}$, corroborando os resultados deste estudo que, diferentemente de publicações anteriores, Silva $(2011)^{13}$ e Loh e Holton $(2000)^{7}$, não estudou o antibiograma das cepas identificadas.

Dentre as enterobactérias de interesse, destacam-se a E. coli, que permanece a bactéria mais comumente isolada, em geral altamente suscetível à antibióticos. ${ }^{8,16}$ A Pseudomonas aeruginosa é o segundo patógeno mais isolado, com cepas multirresistentes. E, finalmente, as Klebsielas, com perfil de elevada resistência, que representam um grande problema para o controle das IRAS nos últimos anos. ${ }^{14,16}$

Outro importante microrganismo é o Staphylococcus aureus, patógeno gram positivo dominante, com perfil de progressiva resistência a antibióticos, como o MRSA (estafilococo meticilina-resistente) e VRE (estafilococo vancomicina resistente), prevalentes há décadas nas IRAS. ${ }^{18,19}$

O controle das IRAS e da disseminação de bactérias resistentes torna-se um desafio, uma vez consideradas suas repercussões sociais e no sistema de saúde, como a diminuição da produtividade e da qualidade de vida para o paciente, obstrução de leitos e elevação dos custos da internação hospitalar. A este quadro acrescenta-se que $14 \%$ dos óbitos podem ser atribuídos às IRAS. ${ }^{20}$

No intuito de minimizar riscos aos usuários e profissionais em formação, a adesão às medidas preventivas deve ser estimulada nas escolas de saúde e se estender para o local de trabalho.

$\mathrm{O}$ fato da maioria dos sujeitos, 53 (72\%), serem estudantes e inseridos no ciclo básico de formação - $40(54 \%)$ - fortalece a importância de se estabelecerem ações educativas que assegurem o esclarecimento sobre os riscos de exposição aos pacientes, ao desempenharem suas tarefas, bem como sobre a forma de se protegerem, utilizando o jaleco branco de forma adequada. ${ }^{19}$

Os resultados deste estudo apontaram para o manuseio inadequado dos jalecos brancos e a possibilidade de disseminação de microrganismos no ambiente doméstico dos entrevistados. A maioria dos entrevistados informou não utilizar qualquer cuidado especial de contenção microbiológica, os jalecos são 
guardados em mochilas, junto com outras peças de roupa e até mesmo no banco do carro.

Neste contexto, faz-se necessário impedir a migração de patógenos para o ambiente de guarda, que pode ofertar condições favoráveis ao crescimento, tais como umidade e calor, que podem contribuir para a multiplicação microbiana. ${ }^{20}$

A contaminação do jaleco branco e a disseminação de bactérias entre diferentes ambientes e pacientes estão bem documentadas. Considera-se também importante destacar a frequência e o local de lavagem, além do seu uso em diferentes setores. 7,19,21,22

Sobre a frequência de troca do jaleco, os resultados deste estudo mostraram que quase metade dos entrevistados - 35 (48\%) - troca-o 1(uma) vez por semana. Entretanto, pelo menos $5(7 \%)$ sequer se lembram da última troca.

Na literatura corrente não há consenso sobre a frequência de troca dos jalecos brancos. ${ }^{5,22}$ A recomendação de troca diária de jalecos encontra-se bem descrita em documentos nacionais e internacionais, quando em situação de isolamento. ${ }^{23,24}$

A hipótese de que quanto maior o tempo de uso, maior é a contaminação, é sustentada por Pilonetto et al., (2004) $)^{25}$ e Chaco (2003) ${ }^{26}$, enquanto Burden et al.,(2011) ${ }^{27}$ e Treakle et al., (2009) $)^{22}$ não encontraram diferença significativa entre a contaminação de jalecos limpos e de jalecos em uso por tempo indeterminado.

Wong et al. (1991) ${ }^{4}$ também observou que o nível de contaminação bacteriana não variou com o tempo durante o qual o jaleco estava em uso, mas constatou que o número de colônias aumentou conforme o grau de exposição individual do usuário.

Por outro lado, Sanon $(2012)^{28}$ analisou os uniformes das enfermeiras após plantão, diurno e noturno, que incluiu cuidados a pacientes em unidade de isolamento, e identificou presença significativa de bactérias sobre os uniformes. A presença da contaminação bacteriana pode ter sido uma indicação da ineficácia dos capotes de isolamento como equipamento de proteção individual (EPI), ou, ainda, a inobservância de regras na utilização do EPI pelas enfermeiras.

O uso de jalecos por profissionais de saúde é determinado pelo aspecto de proteção, embora as recomendações de isolamento do Centro de Controle de Doenças- CDC não reconheçam os jalecos brancos como $\mathrm{EPI}^{24}$, ou pela padronização na forma de vestir dos profissionais em ambiente de assistência a saúde. ${ }^{13}$
A frequência da troca dos jalecos é estimulada pela maioria dos estudos..$^{25,26,29}$ Constata-se que o jaleco e/ou uniforme limpo se coloniza rapidamente, podendo alcançar sua contaminação máxima ao final de 8 horas $^{27}, 12$ horas $^{4}$ ou 24 horas $^{30}$ e a contaminação pode se manter por tempo superior a $48 \mathrm{~h} .{ }^{26,27}$ Ainda que as recomendações sobre o tempo de troca dos jalecos brancos sejam inconsistentes, a troca diária parece ser uma alternativa para minimizar riscos..$^{29}$

Quanto à limpeza dos jalecos, estudos anteriores demonstraram que, apesar da contaminação bacteriológica, uma proporção significativa da população estudada lavava os seus jalecos somente ocasionalmente. ${ }^{13,21}$ Para a roupa suja, não há um padrão para o grau de contaminação aceitável. Os microrganismos contaminantes são diferentes entre si na habilidade de se aderirem aos tecidos e sobreviverem ao processo de lavagem da roupa. ${ }^{26,30}$

Os principais patógenos encontrados são bastonetes gram-negativos, destacando-se enterobactérias e Pseudômonas sp. Os gram-positivos mais comuns, os Staphylococcus sp. Enquanto isso, os vírus, como HBV e HIV, estão associados à presença de sangue ou secreções. ${ }^{26,31}$

Entretanto, quando em situação de contaminação grosseira, como respingos de secreção, sangue e outros, é recomendada a retirada imediata da vestimenta e cuidados de contenção específicos, tais como envolvê-la em saco plástico, até a lavagem adequada. $3,21,23$

Os métodos e técnicas de lavagem da roupa, geralmente, associam alguns princípios para melhor alcançar seu objetivo. Os princípios associados no processo de lavagem são de ordem física (mecânica, temperatura e tempo) e química (detergência, desinfecção alvejamento, acidulação e amaciamento). ${ }^{31}$

O processo de lavagem na lavanderia hospitalar, na maioria das vezes, inclui: pré-lavagem com água fria, retirada da sujidade grossa, molho com sabão para retirada de manchas (opcional), enxágue, lavagem com sabão, enxágue, lavagem com desinfetante, clareamento, enxágue e finalização com amaciante. ${ }^{31,32}$

As recomendações para o processamento da roupa hospitalar não se aplicam ao ambiente doméstico. Aylife e Collins (1989) ${ }^{33}$ e Gallagan (1998) ${ }^{34}$ não recomendam a lavagem da roupa em casa pela dificuldade no controle e manutenção da temperatura da água na maioria das máquinas de lavar comercializadas nos EUA testadas em seus estudos. 
A utilização de água quente para a lavagem das roupas facilita a remoção da sujeira e redução da carga bacteriana dos tecidos. ${ }^{35}$ Entretanto, no Brasil, a maioria das máquinas de lavar não utilizam água quente em seus ciclos.

Por outro lado, o uso de produtos químicos pode, igualmente, reduzir o conteúdo bacteriano da roupa suja, desde que suas formulações sejam aplicadas $^{31}$. O hipoclorito é o produto de eleição para a desinfecção de roupa, na dosagem adequada, em torno de 100 partes por milhão, destacadas as características dos tecidos. ${ }^{31,36}$

A lavagem separada do jaleco é recomendada por Patel $(2005)^{35}$ ao aceitar a lavagem doméstica como alternativa, em razão das perdas das peças de roupa e do custo adicional registrado pelos serviços de saúde. Sugere, porém, que sejam respeitadas as etapas básicas do processo de lavagem ${ }^{32}$, incluindo a desinfecção térmica, e uso do ferro de passar como medida complementar. ${ }^{34,35}$

Outro importante aspecto a ser analisado refere-se aos profissionais que mantinham outro vínculo profissional na ocasião do estudo. Os respondentes demonstraram atenção aos preceitos de biossegurança ao relatarem o uso de jalecos brancos diferentes em cada ambiente de trabalho, além da preocupação em tomar banho antes do início das atividades, comportamento favorável à redução da infecção cruzada, podendo servir de exemplo de boa conduta.

Neste estudo, os jalecos apresentaram uma variação de contaminação bastante grande em termos de número de UFC e aspectos de inadequada prática de uso, sugerindo que as formas de uso, de armazenagem e de contenção microbiológica aliadas aos processos de higienização remetam à não observação dos princípios básicos de biossegurança. Estes, então, precisam ser discutidos em bases científicas mais consistentes.

\section{Conclusão}

Os jalecos constituem fontes potenciais de agentes patogênicos e são fontes de infecção cruzada. Configuram-se como um elo importante na cadeia epidemiológica, tanto na prevenção, quanto na transmissão de IRAS e, portanto, seu uso deve ser repensado e a adoção de práticas seguras deve ser estimulada no sentido de minimizar riscos e fomentar o raciocínio preventivo durante a formação acadêmica.

Os estabelecimentos de assistência à saúde são locais complexos, onde se prestam cuidados de saúde a um grande número de pessoas, tendo como resultado a existência de microorganismos com variado perfil de resistência aos quais os profissionais, incluindo aqueles em formação, estão expostos, independentemente da área de atuação. O uso restrito do jaleco em áreas privativas de assistência ao paciente contribui para sua menor contaminação comunitária. Países como o Reino Unido, Bélgica, Austrália e Canadá reconhecem a contaminação dos jalecos dentro e fora do ambiente hospitalar, aumentando o potencial para infecções nosocomiais e para maior circulação de microorganismos potencialmente perigosos nas comunidades. ${ }^{37}$

Ao criar políticas para limitar a exposição de microrganismos hospitalares na comunidade, proibiram o uso de jalecos brancos fora do local de trabalho. Estes países também exigiram que os prestadores dos serviços de saúde fornecessem uniformes limpos para os trabalhadores da saúde. ${ }^{37}$

No Brasil, a legislação vigente, através da Norma Regulamentadora - NR 32 - que estabelece as diretrizes básicas para a implementação de medidas de proteção à segurança de trabalhadores em serviços de saúde, determina que o uniforme limpo seja fornecido pelas instituições de saúde sem ônus para o profissional e que os mesmos não devem utilizá-lo fora do ambiente de trabalho. ${ }^{3}$

A segurança do trabalhador inserido na produção em saúde se alicerça em seu conhecimento e capacitação para prevenir riscos. Contudo, esforços poderiam ser dirigidos a incentivar os trabalhadores a lavarem seus jalecos brancos mais frequentemente. Para tal, este estudo recomenda que mais pesquisas sejam realizadas para avaliar os jalecos brancos como fômites para a transmissão de bactérias patogênicas e gerar alternativas de cuidados com o vestuário do trabalhador de saúde, incluindo a frequência de troca e aspectos da lavagem doméstica.

\section{Referências}

1. Hambraeus A, Ransjö U. Attempts to control clothes borne infection in a burn unit. 1. Experimental investigations of some clothes for barrier nursing. J Hyg. 1977; 79:193-202.

2. Dias Júnior PP. Jaleco: uso correto na hora certa, em local apropriado. Rev Eletrônica Ciências [online].2008 Mai; (43). Disponível em: ttp://www.cdcc.usp.br/ciencia/artigos/art_43/ editorial_ed43.html. [Acesso em 10 maio de 2008].

3. NR 32. Segurança e saúde no trabalho em serviços de saúde. Publicação D.O.U. Portaria GM n. 485, de 11 de novembro de 2005: 16/11/05. Portaria GM n. 939, de 18 de novembro de 2008: 19/11/08. 
4. Wong $\mathrm{D}$, Nye $\mathrm{K}$, Hollis $\mathrm{P}$. Microbial flora on doctors' white coats. BMJ. 1991; 21; 303:1602-04.

5. Carvalho CMRS, Madeira MZA, Tapety FI, Alves ELM, Martins MCC, Brito JNPO. Aspectos de biossegurança relacionados ao uso do jaleco pelos profissionais de saúde: uma revisão da literatura. Texto \& contexto enferm. 2009; 18:355-60.

6. Azambuja EP, Pires DP, Vaz MRC. Prevenção e controle da infecção hospitalar: as interfaces com o processo de formação do trabalhador. Texto \& contexto enferm. 2004; 13 (esp): 79-85.

7. Loh W, Ng VV, Holton J. Bacterial flora on the White coats of medical students. J Hosp Infect. 2000; 45: 65-8.

8. BRASIL. Ministério da Saúde. Agência Nacional de Vigilância Sanitária. Interpretação de dados microbiológicos. Avisa 2009. Disponível em: http://www Anvisa.gov.br/servicosaude /controle/rede_rm/cursos/atm_racional/modulo2/laboratorio2. [Acesso em 10 de Agosto de 2012]

9. Azevedo FM. Microrganismos multirresistentes. In: Oliveira AC. Infecções Hospitalares: epidemiologia, prevenção e controle. $1^{\circ}$ ed. Rio Janeiro: Guanabara Koogan, 2005. v.1, cap 2 parte 7, p. 341-7.

10. Gil AC. Como elaborar projetos e pesquisa. $3^{\underline{a}}$ ed. São Paulo: Atlas; 1995:58.

11. Nesi MAM, Bitu Filho RS, Lima EG, Medeiros AMC, Lima KC. Contaminação jalecos por estudantes de odontologia. Saúde Rev. 2006; 8: 47-54.

12. BRASIL. Ministério da Saúde, Conselho Nacional de Saúde. Resolução no 196 de 10/10/96 sobre pesquisa envolvendo seres humanos. DOU 1996 Oct 16; no 201, seção 1:2 108285.

13- Silva MDM. Caracterização epidemiológica dos microrganismos presentes em jalecos dos profissionais da saúde de um hospital geral. 2011,102 f. Dissertação (Mestrado em Enfermagem) - Escola de Enfermagem, Universidade Federal de Minas Gerais, Belo Horizonte, 2011.

14. BRASIL. Manual de procedimentos básicos em microbiologia clínica para o controle de infecção hospitalar: Módulo I/ Programa Nacional de Controle de Infecção Hospitalar Brasília: ANVISA /Ministério da Saúde, 2000. 56 p.

15. Scheidt KLS. Análise da aderência a procedimentos de prevenção e controle da infecção hospitalar em unidades de terapia intensiva neonatal -2006,151 f. Tese [Doutorado em Ciências da Saúde/Saúde da Criança e da Mulher ] - Instituto Fernandes Figueira/FIOCRUZ] Rio de Janeiro, 2006.

16. Centers For Disease Control and Prevention - CDC. Public Health Service. NNIS Manual, National Nosocomial Infections Surveillance, System. Atlanta, 1994. challenges, and opportunities. Am J Infect Control. 2011; 39:685-9.

17. Wong D, Nye K, Hollis P. Microbial flora on doctors'white coats. BMJ. 1991; 303 (6817):1602-4.

18. Hambraeus A. Transfer of Staphylococcus aureus via nurses, uniforms. J Hyg Camb. 1973;71:799-816.

19. Loveday HP, Wilson JA, Hoffman PN, Pratt RJ. Public perception and the social and microbiological significance of uniforms in the prevention and control of healthcare-associated infections: an evidence review. Br J Infec Control. 2007; 8:10-21.

20. Saloojee H, Steenhoff A. The health professional's role in preventing nosocomial infections. Postgrad Med J. 2001; 77:16-9.

21- Jaleco como fonte de contaminação: prevalência de Escherichia coli e Pseudomonas aeruginosas em tecido de algodão e sintético. In: XX Congresso Brasileiro de Ciência e Tecnologia de Alimentos, 2006, Curitiba- PR vx.
22. Treakle AM, Thom KA, Furuno JP, Strauss SM, Harris AD, Perencevich EN. Bacterial contamination of health care workers' white coats. Am J Infect Control. 2009; 37:101-5. [PubMed:18834751]

23. BRASIL. Agência Nacional de Vigilância Sanitária. Infecção relacionada a assistência à saúde- Módulo 5- Risco ocupacional e medidas de precaução e isolamento/ Agência Nacional de Vigilância Sanitária. São Paulo: Anvisa, 2004. 64 p.

24. Siegel JD, Rhinehart E, Jackson M, Chiarello L. Healthcare Infection Control Practices Advisory Committee, 2007 Guideline for Isolation Precautions: Preventing Transmission of Ifnectious Agents in Healthcare Settings, June 2007. Disponível em: http://www.cdc.gov/ncidod/dhqp/pdf/ isolation2007.pdf. [Acesso em 10 de agosto 2012].

25. Pilonetto $M$, Rosa EA, Brofman PR, Baggio D, Calvário $F$, Schelp C, et al. Hospital Gowns as a vehicle for bacterial dissemination in an intensive care unit. Braz J Infect Dis. 2004; 8:206-10.

26. Chacko L, Jose S, Isac A, Bhat KG. Survival of Nosocomial Bacteria on Hospital Fabrics. Indian J Med Microbiol. 2003; 21: 291.

27. Burden M, Cervantes L, Weed D, Keniston A, Price CS, Albert RK. Newly Cleaned Physician Uniforms and Infrequently Washed White Coats Have Similar Rates of Bacterial Contamination After an 8-Hour Workday: A Randomized Controlled Trial. 2011 Disponível em: www.journalofhospital medicine.com [Acesso em 10 de outubro de 2014].

28. Sanon MA, Watkins S. Nurses' uniforms: How many bacteria do they carry after one shift? J Public Health Epidemiol. 2012; 4: $311-15$

29. Uneke CJ, ljeoma PA. The Potential for Nosocomial Infection Transmission by White Coats Used by Physicians in Nigeria. World Health \& Population. 2010; 11:44-54.

30. Perry C, Marshall R, Jones E. Bacterial contamination of uniforms. J Hosp Infect. 2001; 48: 238-41.

31. BRASIL. Agência Nacional de Vigilância Sanitária. Processamento de roupas em serviços de saúde: prevenção e controle de riscos / Agência Nacional de Vigilância Sanitária. Brasília: Anvisa, 2009.102 p

32. Department of Health. Hospital laundry arrangements for used infect linen. Health service guidelines HSG 95 (18).London: NHS Executive; 1995.

33. Ayliffe GA, Collins B. Laudering of nurses dresses at home. J Hosp Infect. 1989;13:91.

34. Callaghan I. Bacterial contamination of nurses' uniforms: a study. Nursing Stand. 1998;13: 37-42.

35. Patel SN, Murray-Leonard J, Wilson APR. Laudering of hospital staff uniforms at home. J Hosp Infect. 2006; 62:89-93.

36. Rutala WA, Cole EC, Thomann CA, Weber DJ. Stability and bactericidal activity of chlorine solutions. Infect Control Hosp Epidemiol. 1998;19:323-7.

37. Department of Health. Uniforms and workwear: an evidence base for developing local policy. National Health Service, September 17, 2007. Disponível em: http://www.dh.gov.uk/ en/Publicationsandstatistics/Publications/Publications policyandguidance/DH_078433. [Acesso em 23 de outubro de 2013]. 